\title{
Komunikasi Pemasaran Syariah dalam Minat Beli Konsumen
}

\author{
${ }^{1}$ Popon Srisusilawati, ${ }^{2}$ M. Andri Ibrahim, ${ }^{3}$ Randi Ganjar \\ ${ }^{1.2 .3}$ Fakultas Syariah, Universitas Islam Bandung \\ Jl. Tamansari No. 1 Bandung \\ po2nss@gmail.com
}

\begin{abstract}
Abstrak
Komunikasi pemasaran adalah aktivitas pemasaran yang berusaha menciptakan kesadaran atau pengetahuan mengenai produk dengan berbagai atributnya, menginformasikan kelebihan produk, menciptakan citra produk, atau menciptakan sikap positif, preferensi, dan minat membeli produk bersangkutan. Elzata salah satu produk fashion dikota Bandung mengalami pengunjung yang berfluktuasi cenderung menurun tingkat pembeliannya. Keputusan pembelian merupakan elemen penting bagi perusahaan agar tetap bisa mempertahankan produknya. Dalam hal ini diharapkan komunikasi pemasaran dapat mempengaruhi minat beli konsumen. Minat beli konsumen yang tinggi akan mendorong konsumen membeli suatu produk. Rumusan masalah penelitian ini adalah Bagaimana pengaruh komunikasi pemasaran terhadap minat beli konsumen retail store elzatta kota bandung. Penelitian ini bertujuan untuk mengetahui besar pengaruh komunikasi pemasaran terhadap minat beli konsumen retail store elzatta kota bandung. Metode penelitian yang digunakan adalah deskriptif dengan jenis data kuantitatif. Sumber data yang digunakan data primer yaitu data yang di peroleh langsung dari karyawan Elzatta melalui quesioner dan wawancara. Berdasarkan hasil penelitian diperoleh bahwa komunikasi yang diterapkan Elzatta menggunakan media Tv, Brosur, Baligo, Kontes, Member card, potongan harga, acara amal, seminar, donasi, website, katalog, sosial media, wom, penjualan personal. Minat beli konsumen berminat terhadap produk Elzatta dengan skor akhir sebesar 1800 atau sebesar 72\% yang berada dalam kategori setuju dan berpengaruh positif terhadap minat beli konsumen.
\end{abstract}

Kata Kunci: Komunikasi Pemasaran Syariah, Minat Beli, Elzatta

\section{PENDAHULUAN}

Islam di Indonesia merupakan mayoritas terbesar umat Muslim di dunia. Data Sensus Penduduk 2010 menunjukkan ada sekitar $87,18 \%$ atau 207 juta jiwa dari total 238 juta jiwa penduduk beragama Islam. ${ }^{1}$ Tentu hal ini merupakan peluang besar bagi para pelaku usaha busana muslim untuk menjual produknya.

Komunikasi pemasaran adalah aktivitas pemasaran yang berusaha menciptakan kesadaran atau pengetahuan mengenai produk dengan berbagai atributnya, menginformasikan kelebihan produk, menciptakan citra produk, atau menciptakan sikap positif, preferensi, dan minat membeli produk bersangkutan.

Kota Bandung identik sebagai trend fashion paling menonjol di Indonesia. Karena itulah tak jarang Bandung menjadi tuan rumah

\footnotetext{
${ }^{1}$ https://id.wikipedia.org/wiki/Islam_di_Indonesia/. Diakses tanggal 6 november 2018, pukul 22.05 wib
}

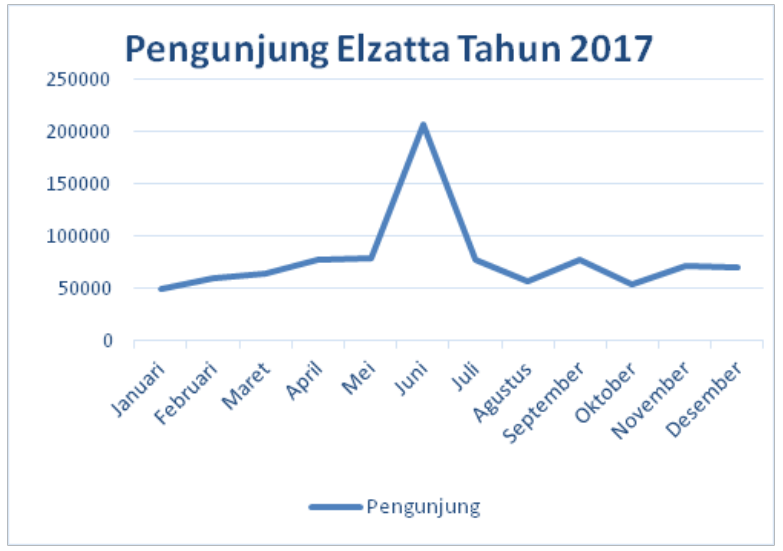

Gambar 1. ${ }^{2}$

festival fashion memunculkan dorongan untuk makin mengukuhkan daerah ini sebagai kota mode, terutama di ranah street style atau modest. Dukungan sumber daya, seperti pabrik

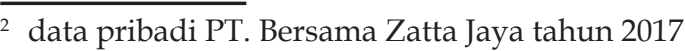




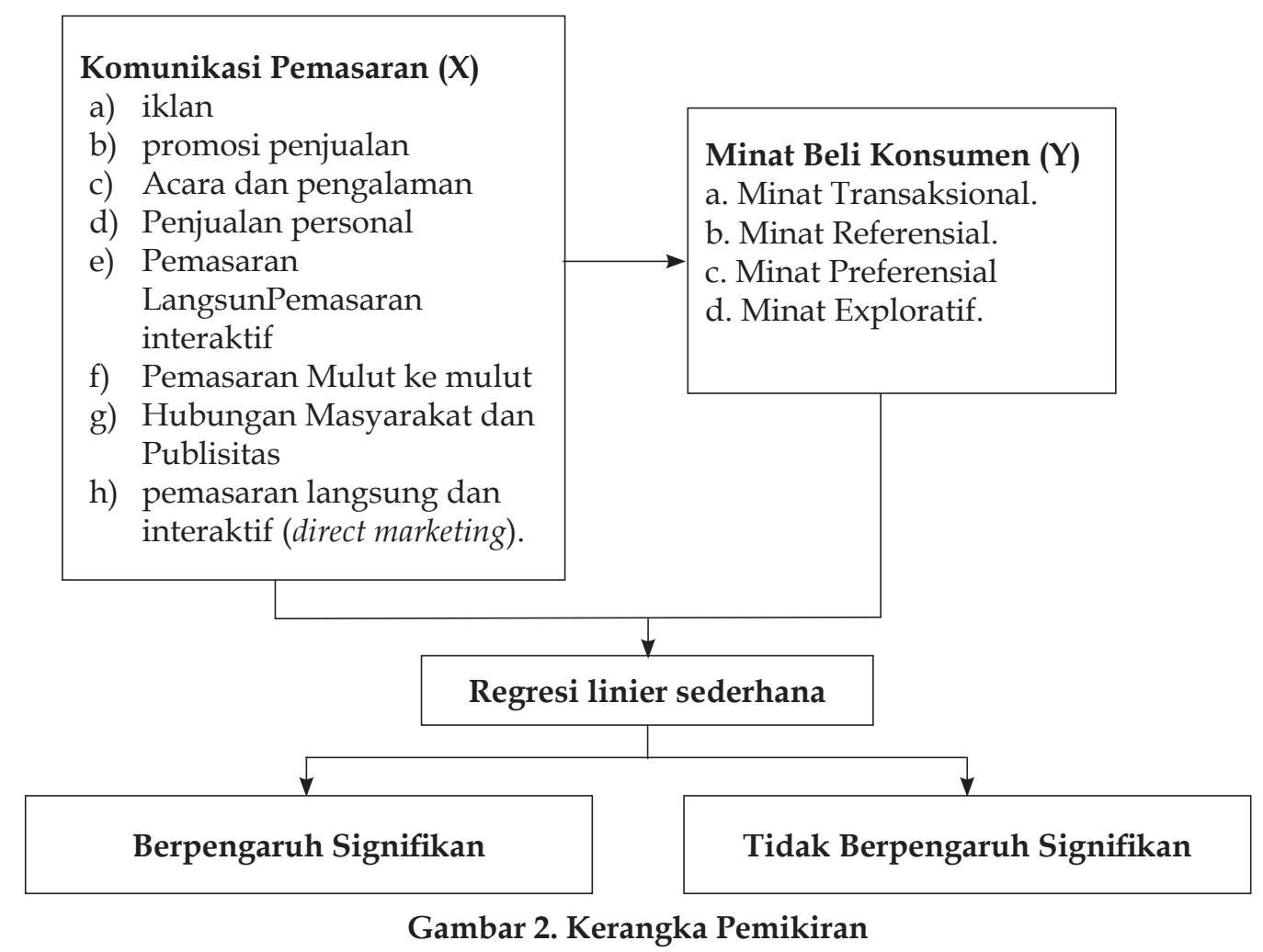

tekstil, garmen, dan konfeksi, ada. ${ }^{3}$ Salah satu yang menjadi daya tarik penulis adalah pada produsen busana muslim Elzatta.

Dari gambar grafik diatas menunjukan bahwa selama satu tahun pengunjung Elzatta store di kota bandung mengalami fluktuasi. Kenaikan terbesar pengunjung Elzatta pada bulan juni dikarnakan pada bulan tersebut adalah bulan ramadhan. Jumlah pengunjung yang berfluktuasi cenderung menurun di indikasikan karena adanya penurunan keputusan pembelian produk Elzatta. Keputusan pembelian merupakan elemen penting bagi perusahaan agar tetap bisa mempertahankan produknya. Dalam hal ini diharapkan komunikasi pemasaran dapat mempengaruhi minat beli konsumen. Minat beli konsumen yang tinggi akan mendorong konsumen membeli suatu produk.

Berdasarkan latar belakang yang telah diuraikan, maka tujuan dalam penelitian ini adalah sebagai berikut:

1. Untuk mengetahui pelaksanaan komunikasi pemasaran di retail store Elzatta kota bandung.

\footnotetext{
${ }_{3}^{3}$ https://kompas.id, diakses tanggal 28 oktober 2018.
}

2. Untuk mengetahui gambaran Minat beli konsumen retail store Elzatta Kota bandung.

3. Untuk mengetahui besar pengaruh komunikasi pemasaran terhadap minat beli konsumen retail store elzatta kota bandung.

Metode penelitian yang digunakan adalah deskriptif secara kuantitatif. Sumber data yang digunakan data primer yaitu data yang diperoleh langsung dari karyawan Elzatta melalui wawancara.

\section{LANDASAN TEORI}

Komunikasi pemasaran merupakan pertukaran informasi dua arah antara pihak atau lembaga yang terlibat dalam pemasaran. Semua pihak yang terlibat dalam proses komunikasi pemasaran melakukan cara yang sama, yaitu mendengarkan, bereaksi, dan berbicara sampai tercipta hubungan pertukaran yang memuaskan. Pertukaran informasi, penjelasan penjelasan yang bersifat membujuk, dan negosiasi merupakan seluruh bagian dari proses tersebut. ${ }^{4}$

\footnotetext{
${ }^{4}$ Philip Kotler dan Keller, "Marketing Management 12 E", New Jersey: Pearson Education, 1997, hlm. 1.
} 
Pemasaran syariah adalah sebuah disiplin bisnis strategi yang mengarahkan proses penciptaan, penawaran, dan perubahan nilai dalam pemasaran dan satu inisiator kepada Stakeholders-nya yang dalam keseluruhan prosesnya sesuai dengan akal dan prinsip muamalah dalam islam. ${ }^{5}$

Dalam kegiatannya islam telah memberikan petunjuk bahwa dalam melakukan sebuah komunikasi pemasaran maka komunikasi yang di lakukan haruslah sesuai dengan aturan yang telah di atur oleh islam salah satunya dengan mengatakan perkataan yang benar seperti yang tertuang dalam ayat sebagai berikut:

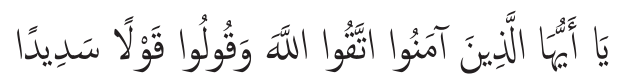

Terjemahannya:

"Hai orang-orang yang beriman, bertakwalah kamu kepada Allah dan katakanlah perkataan yang benar" (QS Al-Ahzab: 70) ${ }^{6}$

Dari ayat di atas sudah jelas bahwa dalam berbicara tentulah kita di anjurkan oleh allah untuk berkata perkataan yang jujur. Begitupun dalam melakukan sebuah komunikasi pemasaran, seorang produsen harus menyampaikan pesan dengan apa adanya tidak melebih-lebihkan.

Komunikasi pemasaran menurut kotler dan keller tujuan komunikasi pemasaran: ${ }^{7}$

a. Memberikan informasi (to inform)

Artinya untuk memastikan agar masyarakat mengetahui dahulu produk tersebut terutama produk yang baru.

b. Membujuk (to persuade)

Komunikasi sudah lebih diarahkan untuk membentuk rasa suka dan referensi masyarakat terhadap suatu produk, agar membentuk preferensi positif untuk produk tersebut.

c. Mengingatkan kembari (reminding)

Tujuan komunikasi disini bertujuan lebih mengingatkan, maksudnya adalah

\footnotetext{
${ }^{5}$ Ilham prisgunanto, “Komunikasi pemasaran”, Bogor: Ghalia Indonesia, 2016, hlm. 3.

${ }^{6}$ Departemen Agama Republik Indonesia, "Al-Qur'an Terjemahan", Jakarta: Pustaka AlMubin, hlm. 426.

7 Bernard T. Widjaja. "Lifestyle Marketing", Jakarta: PT Gramedia, 2009, hlm. 83.
}

mengingatkan berbagai fitur dan ketentuan mengenai produk tersebut, dengan tujuan untuk membantu konsumen yang sudah membeli produk agar merasa terbantu dalam hal penggunaan produk tersebut.

Bauran komunikasi pemasaran menurut kotler dan keller, bauran komunikasi pemasaran merupakan penggabungan dari beberapa model komunikasi pemasaran. merupakan kombinasi alat-alat promosi (komunikasi pemasaran) yang di gunakan. bauran komunikasi pemasaran terdiri dari 2 yaitu : ${ }^{8}$

a. Above the line Yaitu alat promosi yang pendengar sasarannya masal atau banyak yaitu :

1) Periklanan (Advertising)

2) Promosi penjualan (Sales Promotion)

3) Acara dan Pengalaman (Event $\mathcal{E}$ experience)

4) Hubungan Masyarakat dan publisitas (Public Relation E publicity)

$b$. bellow the line yaitu alat promosi yang pendengar sasarannya perorangan.

1) Pemasaran Langsung (Direct Marketing)

2) Pemasaran Interaktif (Interactive Marketing)

3) Pemasaran dari Mulut ke mulut (Word Of Mouth Marketing)

4) Pemasaran personal (Personal Selling)

Minat (Interest) digambarkan sebagai situasi dimana konsumen belum melakukan suatu tindakan, yang dapat dijadikan dasar untuk memprediksi perilakuk atau tindakan tersebut. Minat merupakan perilaku yang muncul sebagai respon terhadap suatu objek yang menunjukkan keinginan pelanggan untuk melakukan pembelian. ${ }^{9}$

Menurut Ferdinand (2002:129), minat beli dapat diidentifikasi melalui indikator indikator sebagai berikut : ${ }^{10}$

1) Minat transaksional

Yaitu kecenderungan seseorang untuk membeli produk. Hal ini bermaksud

\footnotetext{
${ }^{8}$ Philip kotler dan Kevin keller, "Manajemen Pemasaran", jakarta : penerbit erlangga, 2008, hlm. 186.

9 Philip Kotler, "Manajemen Pemasaran,Jilid I dan II", Jakarta: PT.indeks, 2005, hlm.15.

${ }^{10}$ Ferdinand, "Manajemen Pemasaran. Edisi Pertama. Jilid 1", Jakarta: Erlangga, 2002, hlm. 129.
} 
yakni konsumen telah memiliki minat untuk melakukan pembelian suatu produk tertentu yang ia inginkan.

2) Minat referensial

Yaitu kecenderungan seseorang untuk mereferensikan produk kepada orang lain. Hal ini bermaksud yakni seorang konsumen yang telah memiliki minat untuk membeli akan menyarankan orang terdekatnya untuk juga melakukan pembelian produk yang sama.

3) Minat preferensial

Yaitu minat yang menggambarkan perilaku seseorang yang memiliki pilihan utama pada produk tersebut. Preferensi ini hanya dapat diganti jika terjadi sesuatu dengan produk preferensinya.

4) Minat eksploratif

Minat ini menggambarkan perilaku seseorang yang selalu mencari informasi mengenai produk yang diminatinya dan mencari informasi untuk mendukung sifatsifat positif dari produk tersebut.

Penelitian dari Universitas Sebelas maret, pada tahun 2013 dengan judul "Analisis Strategi Komunikasi Pemasaran Dalam Meningkatkan Jumlah Konsumen" yang di tulis oleh Djoko santosa. Menggunakan metode penelitian kualitatif deskriptif. Dengan hasil penelitian bahwa, Penelitian ini menggunakan metode penelitian kualitatif dan lebih menekankan kepada kualitas pemahaman perusahaan mengenai masalah yang di teliti. ${ }^{11}$

Penelitian selanjutnya pada sebuah jurnal sains pemasaran indonesia yang di lakukan oleh Bintoro pada tahun 2016 dengan judul Pengaruh Komunikasi Pemasaran, Kepercayaan Merek Dan Ekuitas Merek Terhadap Keputusan Pembelian, yang menjadi Fokus penelitian ini terfokus pada lima variabel yang terdiri dari Pengaruh Komunikasi Pemasaran, Kepercayaan Merek Dan Ekuitas Merek Terhadap Keputusan Pembelian. ${ }^{12}$

\footnotetext{
${ }^{11}$ Djoko santosa dkk, "Analisis Strategi Komunikasi Pemasaran Dalam Meningkatkan Jumlah Konsumen". Universitas Sebelas maret, 2013.

${ }^{12}$ Bintoro, (dkk.), "Pengaruh Komunikasi Pemasaran,
}

Adapun penelitian dari Universitas Islam Negri Sunan Kalijaga oleh Septiani Maulina Rahayu pada tahun 2014 dengan judul Strategi komunikasi pemasaran dalam bisnis kuliner berbasis mix media, yang menjadi fokus penelitian ini yaitu dengan studi deskriptif kualitatif, hasil dari penelitian ini yaitu menunjukan kesesuaian pengaplikasian komunikasi pemasaran pada sebuah bisnis kuliner. ${ }^{13}$

Adapun penelitian dari Universitas Islam Bandung oleh Popon Srisusilawati pada tahun 2017 dengan judul Kajian Komunikasi pemasaran terpadu dalam mendorong keputusan pembelian jasa perbankan, yang menjadi fokus penelitian ini yaitu dengan studi kuantitatif, hasil dari penelitian ini menunjukan bagaimana keputusan konsumen untuk menjadi nasabah perusahaan jasa perbankan. $^{14}$

Selanjutnya adapun penelitian dari Universitas Islam Bandung oleh Annisa Wulandari pada tahun 2016 dengan judul The Analysis of Islamic Marketing Strategy on the Implementation of El Zatta Marketing Strategy of PT Zatta Mulya Industry Branch Bandung, yang di fokuskan dalam penelitian ini yaitu dengan studi kuantitatif yang menyimpulkan mengenai kesesuaian komunikasi pemasaran syariah yang di terapkan oleh Elzatta. ${ }^{15}$

\section{HASIL PENELITIAN DAN PEMBAHASAN}

Pelaksanaan komunikasi pemasaran yang di lakukan oleh elzatta yaitu terdapat delapan bentuk bauran pemasaran yang telah di koordinasi oleh bagian Business development manager yang terdiri dari beberapa bagian divisi yaitu ada bagian head sales yang

Kepercayaan Merek dan Ekuitas Merek Terhadap Keputusan Pembelian", jurnal sains pemasaran Indonesia, Volume XV, No. 1, Mei 2016.

${ }^{13}$ Septiani Maulina, "Strategi komunikasi pemasaran dalam bisnis kuliner berbasis mix media", Universitas Islam Negri Sunan Kalijaga, 2014.

${ }^{14}$ Srisusilawati, Popon. "Kajian Komunikasi Pemasaran Terpadu Dalam Mendorong Keputusan Pembelian Jasa Perbankan." AMWALUNA: Jurnal Ekonomi dan Keuangan Syariah 1.1 (2017): 1-18.

${ }^{15}$ Annisa Wulandari, "The Analysis of Islamic Marketing Strategy on the Implementation of El Zatta Marketing Strategy of PT Zatta Mulya Industry Branch Bandung", Universitas Islam Bandung, 2016. 
bertugas untuk menentukan aktifitas bulanan atau tahunan mengenai target penjualan dan harga yang akan di pasarkan dan menentukan adanya potongan harga sebuah produk. Selanjutnya ada bagian dari divisi head designer yang bertugas untuk menentukan bagaimana desain dari iklan yang ingin dibuat untuk di publish kepada publik sehingga dapat menarik minat konsumen, lalu ada bagian head merchandise yang bertugas menentukan dan menganalisa jenis dan bentuk display barang yang akan di dagangkan sehingga barang tersebut laku dan terlihat menarik oleh pelanggan. Dan yang terakhir ada bagian head marketing \& promotion yang memiliki tugas untuk melakukan untuk membuat dan melakukan perencanaan mengenai pemasaran dan promosi yang akan di dilaksanakan oleh perusahaan.

Sepanjang tahun 2017 dan 2018 Elzatta telah melakukan berbagai bentuk komunikasi pemasaran baik komunikasi pemasaran above the line dan bellow the line. Contohnya yaitu Elzatta telah menerapkan iklan televisi yang berdurasi 15 detik di tv one pada saat dan sebelum bulan ramadhan pada tanggal 14 mei 2018. Dalam iklan Elzatta hanya membuat ucapan selamat menunaikan ibadah puasa dari iklan tersebut Elzatta tidak menyisipkan kejelasan produk yang di unggulkannya.

Lalu Ezatta menerapkan kartu keanggotaan pada gambar 3 secara gratis untuk konsumen yang telah membeli lebih dari 3 produk Elzatta, dengan kartu keanggotaan tersebut maka konsumen mendapatkan potongan harga member sebesar 10\% dari tiap pembeliannya. Namun dalam membercard ini elzatta hanya menerapkan keunggulan keanggotaannya hanya potongan harga pada beberapa produk saja.Elzatta pun membuat brosur dan baliho yang disediakan di setiap retail store namun penerapannya hanya di beberapa tempat saja yang membuat penyampaian informasi mengenai baligo tersebut kurang tersebar secara masal kepada masyarakat.

Elzatta pun mengadakan acara kontes wajah Elzatta yang di adakan setiap tahunnya yang dimana peserta kontes nantinya akan menjadi icon produk elzatta di tahun tersebut dengan syarat menggunakan produk Elzatta.
Namun dalam informasi acara tersebut kurang diketahui oleh masyarakat secara luas karna tidak semua media yang di keluarkan oleh Elzatta memaparkan reward secara rinci apa saja yang akan di peroleh dari kontes tersebut.

Elzatta telah membuat beberapa acara kemanusiaan untuk membantu sesama contohnya yaitu pada bulan november $2017 \mathrm{di}$ bangladesh Elzatta telah memberikan bantuan pembangunan madrasah untuk pengungsi rohingya. Untuk membangun hubungan dengan masyarakan Elzatta memberikan donasi kepada bencana lombok pada 10 agustus melalui pembelian produk gelang Elzatta dan dana yang terkumpul dari penjualan gelang tersebut sebesar Rp 27.674.600,-. Dalam kegiatan tersebut dengan pembelian gelang kurang efektif karna tidak semua orang di indonesia menggunakan gelang yang terbuat dari karet tersebut.

Elzatta pun telah mengadakan seminar dengan bekerja sama dengan berbagai kampus dengan tema Elcorps goes to campus pada tahun 2018 di Universitas Pendidikan Indonesia dengan judul build the brand and be a creativepreneur pada 27 maret 2018 namun dalam pamflet tersebut tidak ada kejelasan mengenai gratis atau tidaknya acara tersebut.

Elzatta telah menyediakan website yang bisa di akses oleh konsumen Elzatta yang di dalamnya berisi katalog dan berbagai informasi mengenai Elzatta, konsumen dapat langsung berbelanja secara online di website tersebut.

Sosial media merupakan hal yang sangat penting oleh karna itu Elzatta pun tak lepas untuk memanfaatkan sosial media sebagai alat promosinya seperti facebook, twitter dan istagram. Dalam instagram Elzatta telah membuat sebuah hastag yang dapat di lihat oleh konsumen mengenai review dari konsumen lain mengenai produk elzatta dengan hastag saya pakai Elzatta. ${ }^{16}$

Namun Elzatta kurang dalam memaksimalkan sosial medianya, Elzatta tidak menggunakan seorang influencer yang dikenal oleh banyak masyarakat sehingga dari setiap

\footnotetext{
${ }^{16}$ Wawancara dengan ibu tika Mulya,business development manager Elcorps Bandung, di Elcorps Bandung tanggal 19 desember 2018.
} 


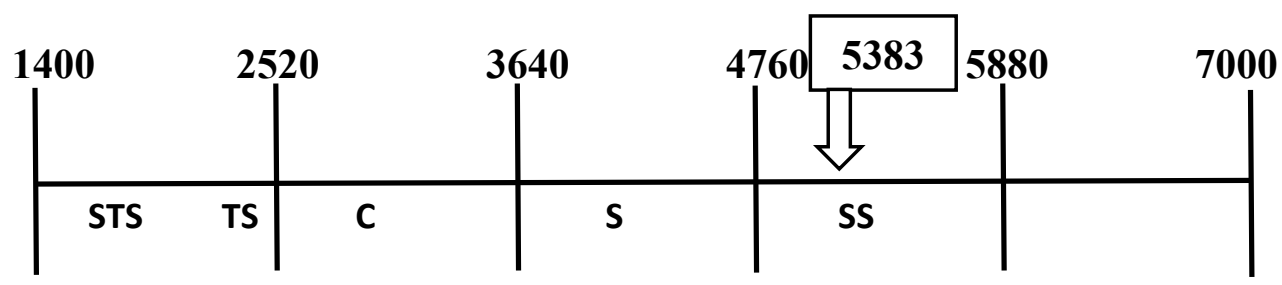

Gambar 3. Garis Kontinum Variabel X (Komunikasi Pemasaran) ${ }^{17}$

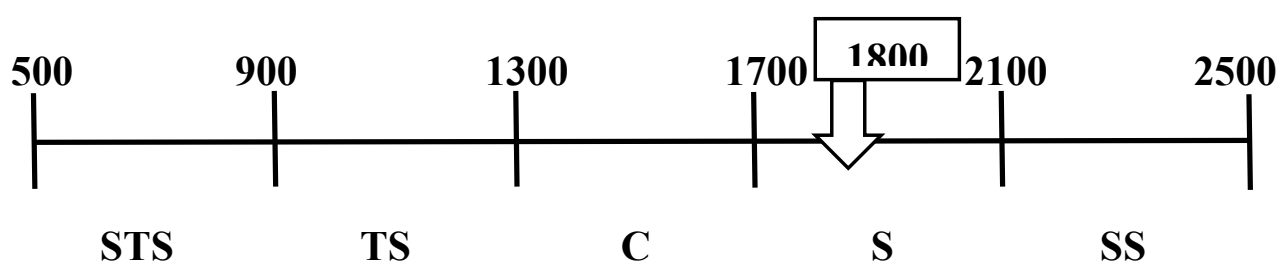

Gambar 4. Garis Kontinum Variabel Y (Minat Beli Konsumen) ${ }^{18}$

postingan yang dibuat tidak mendapat respon yang banyak dari konsumen.

Gambaran tanggapan konsumen mengenai pelaksanaan komunikasi pemasaran yang dilakukan oleh Elzatta di kota bandung, peneliti memberikan pernyataan yang harus dijawab dengan skala likert terhadap unsurunsur yang diteliti.

Variabel komunikasi pemasaran menggunakan 8 dimensi dan 14 indikator yang digunakan dalam mengukur variabel komunikasi pemasaran dengan menggunakan kuesioner.

Dalam gambar 3 dapat dilihat bahwa dari seluruh total indikator dari variabel $X$ yang menghasilkan sebanyak 14 buah pertanyaan yang hasilnya dibagi dalam 5 klasifikasi penilaian, dan diperoleh hasil akhir sebesar 5383 atau sebesar $77 \%$ yang berada dalam kategori setuju, hal ini menunjukan bahwa komunikasi pemasaran yang dilakukan oleh Elzatta kota Bandung telah sampai dengan baik kepada konsumen.

Dalam gambar 4 dapat dilihat bahwa dari seluruh total indikator dari variabel $Y$ yang menghasilkan sebanyak 5 buah pertanyaan yang hasilnya dibagi dalam 5 klasifikasi penilaian, dan diperoleh hasil akhir sebesar 1800 atau sebesar $72 \%$ yang berada dalam kategori setuju, hal ini menunjukan Minat beli konsumen terhadap produk Elzatta kota

\footnotetext{
${ }^{17}$ Olah data kuisioner garis kontinum, 2018

${ }^{18}$ Olah data kuisioner garis kontinum minat beli, 2018
}

Bandung memiliki kecenderungan minat baik. Analisis Pengaruh Komunikasi Pemasaran terhadap Minat Beli konsumen produk Elzatta.

Tabel 1. Analisis regresi linier sederhana ${ }^{19}$

Coefficients $^{a}$

\begin{tabular}{|c|c|c|c|c|c|c|}
\hline \multirow{2}{*}{\multicolumn{2}{|c|}{ Model }} & \multicolumn{2}{|c|}{$\begin{array}{c}\text { Unstandar- } \\
\text { dized } \\
\text { Coefficients }\end{array}$} & \multirow{2}{*}{$\begin{array}{c}\begin{array}{c}\text { Standar- } \\
\text { dized } \\
\text { Coefficients }\end{array} \\
\text { Beta }\end{array}$} & \multirow{2}{*}{$t$} & \multirow{2}{*}{ Sig. } \\
\hline & & B & $\begin{array}{l}\text { Std. } \\
\text { Error }\end{array}$ & & & \\
\hline \multirow[t]{2}{*}{1} & (Constant) & 9.610 & 2.318 & & 4.146 & .000 \\
\hline & $X$ & .156 & .043 & .346 & 3.645 & .000 \\
\hline
\end{tabular}

Dari output di atas diketahui nilai kontstanta dan koefisien regresi sehingga dapat dibentuk persamaan regresi linier berganda sebagai berikut:

$\alpha=9,610$, artinya jika variabel Komunikasi Pemasaran (X) maka variabel Minat beli konsumen (Y) akan bernilai 9,610 satuan.

$\beta=0,346$, artinya jika Komunikasi pemasaran $(X)$ meningkat sebesar satu satuan dan variabel lainnya konstan, maka variabel Minat Beli Konsumen (Y) akan meningkat sebesar 0,346 satuan.

Tanda (+) menandakan arah hubungan searah, sedangkan tanda (-) menandakan arah hubungan yang berbanding terbalik antara variabel independen $(\mathrm{X})$ dengan variabel dependen $(Y)$.

\footnotetext{
${ }^{19}$ Olah data kuisioner regresi sederhana, 2018
} 
Berdasarkan hasil uji regresi linear Sederhana di atas, semua variabel menunjukan arah hubungan yang searah $(+)$ antara variabel independen (Komunikasi Pemasaran) dengan variabel dependen (Minat Beli Konsumen).

\section{SIMPULAN}

Hasil penelitian mengenai pengaruh komunikasi pemasaran terhadap minat beli konsumen retail store Elzatta di kota bandung, maka dapat disimpulkan sebagai berikut:

Komunikasi pemasaran yang di lakukan oleh Elzatta terdapat beberapa dimensi yang terbagi dalam kategori above the line dan bellow the line yang masing masing memiliki beberapa indikator di antaranya pada iklan terdapat Iklan Tv, Brosur, Baligo, untuk promosi penjualan Elzatta menerapkan melalui Kontes, Member card dan potongan harga, dalam acara yang telah di terapkan oleh Elzatta yaitu acara amal, seminar, dan donasi, sedangkan pemasaran interaktif yang ada yaitu website yang di dalamnya terdapat katalog dan tak lepas memanfaatkan sosial media sebagai alat promosi yang di dalamnya terdapat review positif dari konsumen yang telah menggunakan produk Elzatta, dan di retail store Elzatta di kota bandung terdapat pramuniaga yang memberikan pelayanan tentang produk yang dipasarkan.

Minat beli konsumen berminat terhadap produk Elzatta dengan skor akhir sebesar 1800 atau sebesar $72 \%$ yang berada dalam kategori setuju, hal ini menunjukan Minat beli konsumen terhadap produk Elzatta kota Bandung memiliki rata-rata kecenderungan minat dengan kategori baik.

Bedasarkan hasil dari penelitian yang telah dilakukan menunjukan bahwa Komunikasi pemasaran (X) memberikan pengaruh terhadap minat beli konsmen (Y) yang menunjukan thitung ᄀadalah 3,645 sedangkan ttabel adalah 1,660. Maka thitung > ttabel $(3,645>1,660)$ dapat di simpulkan bahwa secara parsial terdapat pengaruh positif dari komunikasi pemasaran terhadap minat beli konsumen.

\section{DAFTAR PUSTAKA}

Annisa Wulandari, "The Analysis of Islamic Marketing Strategy on the Implementation of El Zatta Marketing Strategy of PT Zatta Mulya Industry Branch Bandung", Universitas Islam Bandung, 2016.

Bernard T. Widjaja. "Lifestyle Marketing", Jakarta: PT Gramedia, 2009.

Bintoro, (dkk.), "Pengaruh Komunikasi Pemasaran, Kepercayaan Merek dan Ekuitas Merek Terhadap Keputusan Pembelian", jurnal sains pemasaran Indonesia, Volume XV, No. 1, Mei 2016.

Data pribadi PT. Bersama Zatta Jaya tahun 2017 Departemen Agama Republik Indonesia, "AlQur'an Terjemahan", Jakarta: Pustaka AlMubin,

Djoko santosa dkk, "Analisis Strategi Komunikasi Pemasaran Dalam Meningkatkan Jumlah Konsumen". Universitas Sebelas maret, 2013.

Ferdinand, "Manajemen Pemasaran. Edisi Pertama. Jilid 1", Jakarta: Erlangga, 2002.

Https://id.wikipedia.org/wiki/Islam_di_ Indonesia/. Diakses tanggal 6 november 2018, pukul 22.05 wib

Https:/ /Kompas.Id, diakses tanggal 28 oktober 2018.

Ilham prisgunanto, "Komunikasi pemasaran", Bogor: Ghalia Indonesia, 2016.

Philip Kotler dan Keller, "Marketing Management 12 E ", New Jersey: Pearson Education, 1997.

Philip kotler dan Kevin keller, "Manajemen Pemasaran", Jakarta: penerbit erlangga, 2008.

Philip Kotler, "Manajemen Pemasaran,Jilid I dan II", Jakarta: PT.indeks, 2005.

Srisusilawati, Popon. "Kajian Komunikasi Pemasaran Terpadu Dalam Mendorong Keputusan Pembelian Jasa Perbankan." AMWALUNA: Jurnal Ekonomi dan Keuangan Syariah 1.1 (2017): 1-18.

Septiani Maulina, "Strategi komunikasi pemasaran dalam bisnis kuliner berbasis mix media", Universitas Islam Negri Sunan Kalijaga, 2014. 